\title{
Editorial
}

\section{Responsabilidad social en la era de la globalización*}

L a humanidad se encuentra hoy día en una encrucijada. El mundo está aceleradamente interrelacionado por la comunicación de ideas y valores culturales, por la rápida movilidad de los recursos de capital y por un mercado global que vuelve menos significativas que en cualquier otra época de la historia moderna las fronteras entre naciones-estados. Particularmente en la vida económica, las gentes del mundo están ligadas como nunca antes. Esta es una fuente de confianza para la profundización de un verdadero sentido mundial de que todos los hombres y mujeres de este planeta son hermanos y hermanas en una familia global, creada por un Dios y teniendo un destino común.

Sin embargo, la paradoja del momento es que este proceso de globalización está llevando simultáneamente el incremento de un mundo roto e injusto. Las tradiciones culturales que dan significado a las vidas de gentes enteras se hallan amenazadas. El mercado global enriquece a algunas empobreciendo otras.

Muchas comunidades - tanto en mundos en vías de desarrollo como en los desarrollados- están framentadas a causa de las dinámicas del mercado. Como lo ha dicho el Papa Juan Pablo II, este mercado global opera "sobre sus cabezas", marginando a muchos de la participación en las instituciones globales emergentes. El resultado es una creciente desigualdad, disminución de la calidad de vida y aún de la expectativa de vida para muchos y una ascendente impotencia para los más vulnerables.

La paradoja de la globalización confronta así a la raza humana con un reto distinto de cualquier otro que haya tenido que enfrentar en la historia pasada: Cómo ser una comunidad a escala mundial a la vez respetando la dignidad de 
todas las subcomunidades que conforman la familia humana alrededor del mundo.

\section{Signos de los tiempos}

Un aspecto clave de la paradoja de la globalización es que personas distintas hacen divergentes aseveraciones sobre sus consecuencias positivas o negativas. Estos desacuerdos se deben en parte a los diferentes puntos de vista sociales desde los cuales se consideran las emergentes realidades globales. Para algunos, la globalización es un largo, positivo y esperanzador proceso con algunos aspectos negativos que deben ser atendidos a través de reformas incrementadas. Para otros, las consecuencias de la globalización son vistas como grandemente destructivas y las esperanzas que inspira como muy lejanas en el distante futuro. Además, en años recientes ha habido una explosión de enseñanza social católica relevante a la realidad de la globalización, aunque esta enseñanza no es ni ampliamente conocida como tampoco asumida por mucha gente de fe.

El resultado es que esta enseñanza social no se ha beneficiado con el examen de la práctica y la evaluación crítica que merece en las nuevas circunstancias. Es importante destacar algunos de los signos claves de los tiempos, que demandan una reflexión más profunda, si es que los desafíos de la globalización van a ser atendidos.

- La globalización tras un aumento en el crecimiento económico en muchas partes del mundo para beneficio de alguna gente, sin embargo aún continúa ampliándose en todas partes la brecha entre ricos y pobres.

- La globalización estimula el comercio internacional y la comunicación. Sin embargo intensifica la destrucción de las comunidades locales y aún nacionales. Toda la información indica que la desigualdad está aumentando significativamente en todo el mundo; esta desigualdad en sí misma conduce a la reducción de la solidaridad social y al debilitamiento de la comunidad. Son debilitadas las comunidades nacionales y disminuye el poder de los gobiernos nacionales de asegurar el bien común de sus gentes.

- Con la globalización, la reducción y la gestión externa aumenta la competitividad de muchas empresas y ayuda a mantener su competitividad y productividad. Pero durante el proceso muchos trabajadores ven eliminados sus otrora estables trabajos y pocos reemplazos a la vista. En este ambiente el derecho de los trabajadores a organizarse es seriamente comprometido, aumentando además la vulnerabilidad de casi todos los empleados.

- El comercio global sirve a las necesidades de mucha gente proporcionando numerosos productos deseables por ellos, a precios bajos. Pero el comercio global de armas y el tráfico de drogas tiene enormes efectos destructivos en la 
seguridad y salud de muchas comunidades.

- Muchos en la comunidad de negocios y en otros sectores de la sociedad civil han trabajado para promover la inversión de responsabilidad social, para crear códigos generaba de conducta de negocios y formar sociedades con grupos locales, buscando el bienestar de aquellos afectados por tendencias globales. Aún la estrategia de la Organización Mundial del Comercio y una ideología que ve los mercados sin obstáculos como algo esencial sugiere que tales medidas podrían ser desafiadas como injustas restricciones en lo relativo a comercio.

- Instituciones financieras internacionales buscan regular los flujos de crédito y los términos del comercio en forma que estimulen la eficiencia y la productividad de los países en desarrollo. La carga de las condiciones que estas instituciones establecen en lo relativo a reducciones de crédito y deuda es soportada, la mayoría de veces, desproporcionadamente por los miembros más vulnerables y pobres de las comunidades afectadas, puesto que tales condiciones incluyen a menudo la reducción del rol del gobierno, recortes en apoyo a la educación, salud y otros servicios sociales. Tales programas de ajuste económico ofrecen, sí, beneficios al rico y dañan al pobre en formas desproporcionadas.'

- La transferencia de tecnología global incrementa la capacidad productiva, genera nuevos trabajos y estimula dimensiones importantes del bienestar social. Pero el desigual acceso a esta tecnología conduce a una creciente desigualdad de poder, influencia política y habilidad para dar forma a las decisiones económicas que afectan el bien común, especialmente el bienestar del pobre. Mientras exista la tecnología que pueda alimentar a cada quien en el mundo, aumentará el número de gente hambrienta.

- La conciencia de la necesidad de proteger el ambiente natural está creciendo a través del mundo, como es sabido que seres humanos en todas partes comparten un hogar común en esta tierra. Pero esta conciencia no va acompañada de una voluntad por encarar las formas en las que el mundo natural es habitualmente tratado como un artículo, los límites al uso de recursos naturales finitos y los niveles de consumo que la biósfera puede tolerar. A menudo el pobre es culpado por tener demasiados niños mientras que los acaudalados no son tomados en cuenta por consumir desproporcionadamente los limitados recursos del planeta.

- Las nuevas oportunidades de empleo y el desempleo producidos por lo globalización han creado un flujo de emigrantes dentro y entre países. Mucha de esta gente emigrante se hallan en competencia con otros trabajadores pobres, a menudo minorías raciales y étnicas, exacerbando las ya existentes pugnas raciales, étnicas y nacionales.

- Mientras un creciente número de mujeres se han movido hacia el mercado de trabajo pagado, permanecen vulnerables a las peligrosas condiciones labora- 
les y todavía soportan cargas de trabajo doméstico no pagado.

- Todos estos signos de nuestro tiempos demandan decisión y acción. Los retos que generan provienen de instituciones globales y posibilidades que han sido creadas por acciones y decisiones humanas en el pasado.

Viendo hacia el futuro, la confianza debe ser mantenida que las decisiones humanas y las acciones de hoy pueden animar lo positivo y reducir los aspectos negativos de la globalización. Merecen apoyo las muchas personas y comunidades que se han dado a este esfuerzo.

\section{Un desafío al Espíritu}

Responder a estos desafíos exige pensamiento innovador, experimentación valiente y compromiso moral con la justicia esperada por todos los habitantes de este globo. Pero la encrucijada en la cual nos encontramos es sobre todo una encrucijada del espíritu. Por lo tanto requiere una respuesta enraizada en espiritualidad y visión imaginativa. El espíritu de Dios está activo en el mundo buscando la plenitud de vida para toda la gente de Dios. La tareas de toda persona de fe es discernir dónde el espíritu de Dios está trabajando para dar a luz una nueva creación y unir sus esfuerzos a la obra de Dios.

Tales discernimientos exigen una conversión del corazón y la transformación de la sociedad, una reexigencia de valores, una espiritualidad renovada - que revitalice el sentido de nuestra propia dignidad y la dignidad de cada otra persona, nuestro compromiso con la comunidad, y nuestra confianza en la promesa de un Nuevo Cielo y una Nueva Tierra. Apoyados en la historia del Evangelio, la música, la oración ritual y común de la liturgia, como también una cuidadosa reflexión y análisis de las nuevas realidades de una sociedad global, tal espiritualidad puede unir a hombres y mujeres en los niveles más profundos de la experiencia humana, alimentando un deseo de solidaridad que despertará en cada uno de nosotros una preocupación fundamental —una opción preferencialpor aquellos presos de la pobreza, y transformar nuestro entendimiento de la buena vida hacia una que es profundamente buena para todos. Una profunda atención a la presencia del espíritu unificador de Dios puede atraer gente de diversas tradiciones religiosas y reunirlas en formas que enuncien la verdadera comunidad humana global que Dios desea para toda la humanidad. Esto conducirá a relaciones recíprocamente sustentadoras uno con otro y con toda la creación, encontrando a Dios que vive entre nosotros y honrando esa presencia en la forma de tratar al otro con justicia, compasión y amor. Esta renovada espiritualidad alimentará nuestra hambre de significados y atemperará las tentaciones culturalmente cultivadas, al excesivo individualismo, al consumismo, al control y la codicia. Modelará nuestra visión del futuro y las sugerencias críticas para 
llegar a él. Ello inspirará nuevas estructuras sociales de justicia y al respirar vida intensa en ellas.

* Declaración final del Simposio sobre Etica y Globalización Económica; Milwaukee, 27-29 mayo 1997. Traducción libre de Oswaldo Caminos Chávez. 